\title{
Centro de Apoyo a la Tecnología y la Innovación de la Universidad Nacional Autónoma de Nicaragua, Managua
}

\section{Support Center for Technology and Innovation of the National Autonomous University of Nicaragua, Managua}

DOI: $\underline{\text { http://dx.doi.org/10.5377/uyc.v10i16.6142 }}$

Maykol Salazar

catiunan@gmail.com

Universidad Nacional Autónoma de Nicaragua, Managua

(C) UNAN-Managua

Recibido: octubre 2017. Aprobado: octubre 2017.

\section{RESUMEN}

El Centro de Apoyo a la Tecnología y la Innovación de la UNAN-Managua (CATI/UNANManagua) fue instalado el 30 de marzo de 2015 en la Dirección de Extensión Universitaria y en la Facultad de Ciencias e Ingeniería de la UNAN-Managua, a cargo de los docentes Maykol Salazar Betanco y Wilmer Sequeira Calero, respectivamente. En octubre de 2014 se preparó el primer borrador de convenio de instalación del CATI entre la UNANManagua y el Registro de la Propiedad Intelectual. Palabras clave: tecnología, innovación, asesoría, CATI.

\section{SUMMARY}

The Technology and Innovation Support Center of the UNAN-Managua (CATI / UNANManagua) was installed on March 30, 2015 in the University Extension Office and in the School of Science and Engineering of the UNAN-Managua, by Maykol Salazar Betanco and Wilmer Sequeira Calero, respectively. In October 2014, the first draft of the CATI installation agreement between the UNAN-Managua and the Intellectual Property Registry was prepared.

Keywords: technology, innovation, advice, CATI.

El Centro de Apoyo a la Tecnología y la Innovación de la UNAN-Managua (CATI/UNANManagua) fue instalado el 30 de marzo de 2015 en la Dirección de Extensión Universitaria y en la Facultad de Ciencias e Ingeniería de la UNAN-Managua, a cargo de los docentes Maykol Salazar Betanco y Wilmer Sequeira Calero, respectivamente. En octubre de 2014 se preparó el primer borrador de convenio de instalación del CATI entre la UNAN-Managua y el Registro de la Propiedad Intelectual. ${ }^{1}$

\footnotetext{
${ }^{1}$ (Salazar, Referencias de documentos públicos e información contenida en documentos de patentes, artículos científicos y bibliografía técnica, Tecnología a partir de Pitaya, Suplemento Alimenticio con propiedades medicinales y como colorante Natural., 2017)
} 


\section{universidâd}

El CATI/UNAN-Managua fue trasladado a la Dirección de Investigación de Grado a cargo del Vicerrectorado de Investigación de UNAN-Managua procedente de la Dirección de Extensión Universitaria, para mejorar los procesos de Innovación y Emprendimiento de los estudiantes del Grado en septiembre del 2015, iniciando el trabajo del desarrollo de las actividades de protección de la Propiedad Intelectual se inicia la construcción de los preparativos para el funcionamiento del CATI/UNAN-Managua.

La UNAN-Managua forma parte de la Red Regional de los CATÍśs de los países centroamericanos y República Dominicana desde abril del 2017, actualmente la UNAN-Managua es la única universidad que mantiene activo y funcional su CATI en Nicaragua. ${ }^{2}$

\section{Razón Social}

El CATI/UNAN-Managua nace como un espacio para la asistencia científica y técnica facilitando el acceso a la información tecnológica a los: innovadores, investigadores, emprendedores, centros de estudios, pequeñas y medianas empresas del país, mediante los servicios de información básica de normas, gestión y estrategias de propiedad intelectual y revistas científicas.

El CATI/UNAN-Managua tiene como población meta a lo inmediato a docentes, estudiantes y trabajadores en general, y en la medida en que se adquiera experiencia, se irán asumiendo nuevos retos con actores económicos y sociales del entorno de la UNAN-Managua.

\section{Logros}

Registro de la primera solicitud de patente de las universidades en Nicaragua. La UNANManagua a través de la Dirección de Investigación de Grado realiza la primera gestión de la primera solicitud de patente el 16 de enero de $2017 .^{3}$

Registro de la Marca Institucional de la UNAN-Managua. El día dos de octubre de 2017 la UNAN-Managua tendrá registrada su marca Institucional, gestión realizada a través de la Dirección Jurídica y apoyada de la Dirección de Investigación de Grado. ${ }^{4}$

Registro del Primer Derecho de Autor de UNAN-Managua. El 17 de agosto de 2017 se publica en la gaceta el diario oficial el primer registro exitoso por derecho de autor de la UNAN-Managua. ${ }^{5}$

\footnotetext{
2 (Organización Nacional de la Propiedad Intelectual (ONAPI, República Dominicana);, 2017)

3 (Nicaragua Patente no 2016000011l, 2016)

${ }^{4}$ (La Gaceta Nicaragua, 2017)

${ }^{5}$ (La Gaceta Nicaragua, 2017)
} 


\section{REFERENCIAS}

La Gaceta Nicaragua. (2 de Agosto de 2017). La Gaceta Nicaragua. Obtenido de http://www.lagaceta.gob.ni/gaceta-145-miercoles-02-de-agosto-2017/

Organización Nacional de la Propiedad Intelectual (ONAPI, República Dominicana). (2017). Tercera Reunión Centroamericana de Expertos para la creación de una Red Subregional de Centros de Apoyo a la Tecnología y la Innovación (CATI-CARD) en los Países Centroamericanos y la República Dominicana. Santo Domingo.

Salazar, M. (2015). Manual de uso de base de datos e Instalación del CATI/UNAN-Managua. (1 ed., Vol. 1). Managua: Editorial Universitaria.

Salazar, M. (2017). Referencias de documentos públicos e información contenida en documentos de patentes, artículos científicos y bibliografía técnica, Tecnología a partir de Pitaya, Suplemento Alimenticio con propiedades medicinales y como colorante Natural. UNAN-Managua, Managua.

Sequeira, W., \& Salazar, M. (Enero de 2016). Nicaragua Patente $n^{o} 20160000111$.

La Gaceta Nicaragua. (2 de Agosto de 2017). La Gaceta Nicaragua. Obtenido de http://www.lagaceta.gob.ni/gaceta-156-jueves-17-de-agosto-2017/ 